\title{
Detailed Numerical Modeling of Flood Flow in Floodplains with Complex Geometry
}

\author{
P. Valenta, J. Valentová
}

Numerical modeling of flood flow and the evaluation of flood hazards can be based on various numerical models and modeling techniques. One-dimensional $(1 D)$, quasi two-dimensional $(1,5 D)$, two-dimensional $(2 D)$ or three-dimensional $(3 D)$ variants of numerical models can be used. While 3D models are too demanding to be used for flood flow modeling on personal computers, quasi-2D and $2 D$ models can be more widely used to solve even larger practical problems nowadays. Detailed two-dimensional numerical modeling of flood flow in flooded urbanized areas with complex geometry using the $2 D$ depth averaged model is presented in this paper. The governing equations of the model are expressed with a set of depth averaged Reynolds equations consisting of the continuity equation and two momentum equations for the horizontal velocity components. The eddy viscosity, which influences the horizontal turbulent momentum exchange processes, is modeled with the aid of a depth average version of the two-equation $k$ - $\varepsilon$ turbulence model. The partial differential equations are solved numerically with a control volume method using fine non-orthogonal curvilinear grids and a non-staggered variable arrangement. The applicability and advantages of this modeling approach for simulating the flood flow in floodplains with complex geometry, and in urban areas, are illustrated by the results of a pilot study in Choceň and Ústi nad Orlici, towns which were severely affected during the 1997 and 1998 floods in the Czech Republic.

Keywords: numerical modeling, modeling of flood flow, control volume method.

\section{Introduction}

Experience resulting from the extreme flood events in the Czech Republic in recent years have stressed the necessity of further development and practical evaluation of suitable methodologies enabling more detailed investigation of flood flow characteristics in domains with very complex geometry and in urbanised areas. Various numerical models and modeling techniques [1] can be used and are being developed and improved according to the growing performance of computers. The classical approach to the numerical modeling of flood events is based on the application of various types of $1 \mathrm{D}$ models. These models enable the longitudinal water elevation distribution to be estimated along the river axis for the flood peak discharge (steady case calculation), or analyses to be made of flood wave propagation (unsteady simulation). Flooding lines were, and in most cases still are, estimated and officially delimited in the Czech Republic with the use of 1D modeling technology.

Current trends in the field of numerical modeling of flood events are oriented towards the development and practical utility of multi-dimensional models. While 3D models are still too demanding to be used for flood flow modeling, quasi-2D and 2D models can nowadays be more widely used to solve larger practical problems, even on personal computers. These complex models can provide results of substantially higher quality than those of 1D modeling tools. Together with the water elevation distribution, 2D models provide a lot of other detailed information not available in the classical 1D numerical model output (flow pattern evaluation, distribution of velocity magnitudes and directions (velocity fields), streamlines, etc.), which is extremely important information for hydraulic and other follow-up (flood risk, flood damage) analyses of flood events.
The Faculty of Civil Engineering at the Czech Technical University is a co-bearer of the Czech-Swiss FLAMOR (Flood Analyses and Mitigation on the Orlice River) project, which was initiated by the flood events in the Czech Republic in 1997. The project is supported by Swiss Humanitarian Aid and Disaster Relief (SHA+DR). Within the framework of this project a detailed case study dealing with hydraulic and flood risk analyses in the urban areas of Choceň and Ústí nad Orlicí was elaborated. The modeling results for Choceň from this study are used as examples in this paper.

\section{Numerical model}

The applied numerical model is based on the FAST 2D model originally developed in Germany at the Institute for Hydrodynamics in Karlsruhe [2]. The model enables the simulation of free surface steady water flow in domains with complex geometry. Further development of the model, aimed at the design and programming of suitable pre- and post-processing tools, has been carried out by Hydroexpert Ltd., Prague, in cooperation with the Bundesanstalt für Wasserbau in Karlsruhe [3].

\section{Governing equations}

The model is based on the set of depth averaged Reynolds equations often called 'shallow water equations', which can be derived by integration of the Reynolds equations for three dimensional flow over the depth of the water layer [4]. The resulting set of governing equations consists of the continuity equation and two momentum equations for the horizontal velocity components. It can be written in the following form: 


$$
\begin{aligned}
\frac{\partial u_{i}}{\partial t}+u_{j} \frac{\partial u_{i}}{\partial x_{j}}= & -g \frac{\partial}{\partial x_{i}}\left(h+z_{b}\right)+ \\
& +\frac{1}{\rho h} \frac{\partial}{\partial x_{j}}\left(h T_{i j}\right)+S_{i} ; \quad i, j=1,2 \\
\frac{\partial h}{\partial t}+ & \frac{\partial\left(h u_{i}\right)}{\partial x_{i}}=0,
\end{aligned}
$$

where $t$ is the time [s], $h$ is the water depth [m], $z_{b}$ denotes the vertical coordinate of the bottom level [m], $\rho$ is the water density $\left[\mathrm{kg} \cdot \mathrm{m}^{-3}\right], \mathrm{g}$ is the acceleration due to gravity $\left[\mathrm{m} \cdot \mathrm{s}^{-2}\right]$. The velocities $u_{1}$ and $u_{2}\left[\mathrm{~m} \cdot \mathrm{s}^{-1}\right]$ are the depth averaged velocities in the $x_{1}$ and $x_{2}$ directions, the source term $S_{i}\left[\mathrm{~m} \cdot \mathrm{s}^{-2}\right]$ in the momentum equations includes the influence of external forces and stresses, such as bed shear, stress due to wind on the water level and the Coriolis acceleration. The depth-averaged components of the effective stress tensor are defined as the sum of laminar stresses $\tau_{l}$, turbulent stresses $\tau_{t}$ and stresses $\tau_{d}$ resulting from the non-uniform velocity distribution in the vertical direction:

$$
T_{i j}=\frac{1}{h} \int_{z_{b}}^{z_{b}+h}\left(\tau_{i j}^{l}+\tau_{i j}^{t}+\tau_{i j}^{d}\right) \mathrm{d} z .
$$

The individual components are defined as

$$
\begin{aligned}
\tau_{i j}^{l} & =v \rho\left(\frac{\partial u_{i}}{\partial x_{j}}+\frac{\partial u_{j}}{\partial x_{i}}\right) \\
\tau_{i j}^{t} & =-\rho \overline{u_{i}^{\prime} u_{j}^{\prime}} \\
\tau_{i j}^{d} & =-\rho\left(u_{i}-u_{i}^{z}\right)\left(u_{j}-u_{j}^{z}\right),
\end{aligned}
$$

where $v$ in the laminar stress term is the kinematic viscosity $\left[\mathrm{m}^{2} \cdot \mathrm{s}^{-1}\right]$. Turbulent Reynolds stresses are expressed using the turbulent fluctuations of the velocity components $u_{i}^{\prime}$, and the bar denotes an averaging operation. Due to these terms, the system of governing equations is not closed and has to be supplemented with some suitable model of turbulence. The effective stresses $T_{i, j}$ are modeled by the eddy viscosity approach in the model:

$$
T_{i j}=v_{t} \rho\left(\frac{\partial u_{i}}{\partial x_{j}}+\frac{\partial u_{j}}{\partial x_{i}}\right),
$$

where $v_{t}$ is the eddy viscosity $\left[\mathrm{m}^{2} \cdot \mathrm{s}^{-1}\right]$. The eddy viscosity which models the horizontal turbulent momentum exchange processes is calculated with the aid of a depth average version of the $k-\varepsilon$ turbulence model developed by Rastogi and Rodi [5]. In this model the eddy viscosity is related to the turbulent kinetic energy $k\left[\mathrm{~m}^{2} \cdot \mathrm{s}^{-2}\right]$ of the turbulent motion and to its dissipation rate $\varepsilon\left[\mathrm{m}^{2} \cdot \mathrm{s}^{-3}\right]$ by

$$
v_{t}=c_{\mu} \frac{k^{2}}{\varepsilon} .
$$

The horizontal distribution of $k$ and $\varepsilon$ over the modeled domain is calculated by solving partial differential transport equations for these two variables. Due to this modeling approach the final set of governing equations solved in the model consists of a total of five partial differential equations two momentum equations with a continuity equation and two transport equations for the turbulence parameters.

\section{Solution procedure}

The partial differential equations are solved numerically with a finite volume procedure based on a method for pure two-dimensional flow, which is described in detail in Majumdar [6] and Rodi et al [7]. The method employs non-orthogonal curvilinear grids and a non-staggered variable arrangement, i.e., all variables are stored at the center of the control volumes. This technique requires the use of a special momentum interpolation scheme in order to avoid unnatural pressure oscillations (for details, see Majumdar [6]). The scheme further uses Cartesian velocity components and hybrid central/upwind differencing for the discretization of convective terms in the momentum equations. The pressure-velocity coupling is achieved with the SIMPLEC iteration algorithm, in which the momentum equations are solved first with the guessed pressure field, and an improved pressure distribution is then calculated via a pressure correction equation. The resulting system of linear equations at each iteration is solved with the Thomas tridiagonal matrix algorithm (TDMA). The implicit coupling between the pressure and water elevation (or water depth) in the depth average model is solved in an outer iteration loop.

\section{Input data}

The main input data for the model includes:

- geometrical data describing the computational grid,

- geometrical data describing the terrain topography,

- a definition of the fixed non-overflowed obstacles (buildings, dikes, roads, etc.),

- distribution of bottom shear stress parameters (Manning roughness coefficients),

- boundary conditions.

\section{Application to case study}

\section{Study area}

Choceň lies on the Tichá Orlice river at 290 m.a.s.l. It is an industrial center with textile and machinery industry and an important railway junction. The town has a population of 9200 inhabitants (in 1530 houses). The urbanised area (residential and public buildings) covers a surface area of 2.1 square km. Fig. 1 shows an aerial photograph of the flooded town area during the flood in 1997.

\section{Input data and model construction}

The model created for Chocen covers the flooded area about $3.8 \mathrm{~km}$ in length and $1 \mathrm{~km}$ in width. The left and right side boundaries were chosen in such a way that the whole width of the flood plain inundated during the extreme flow events fits into the model area.

The curvilinear computational grid was generated using the model boundaries as input data. The number of control volumes in the longitudinal direction was 1470, while in the transverse direction 500 control volumes were used. The total number of computational cells was 735 000. The large number of control volumes enabled sufficiently detailed modeling of structures in the urban areas (the average size of a control volume was about $2.5 \times 2 \mathrm{~m}$ ). In the next step in constructing the model, all the control volumes located inside buildings 


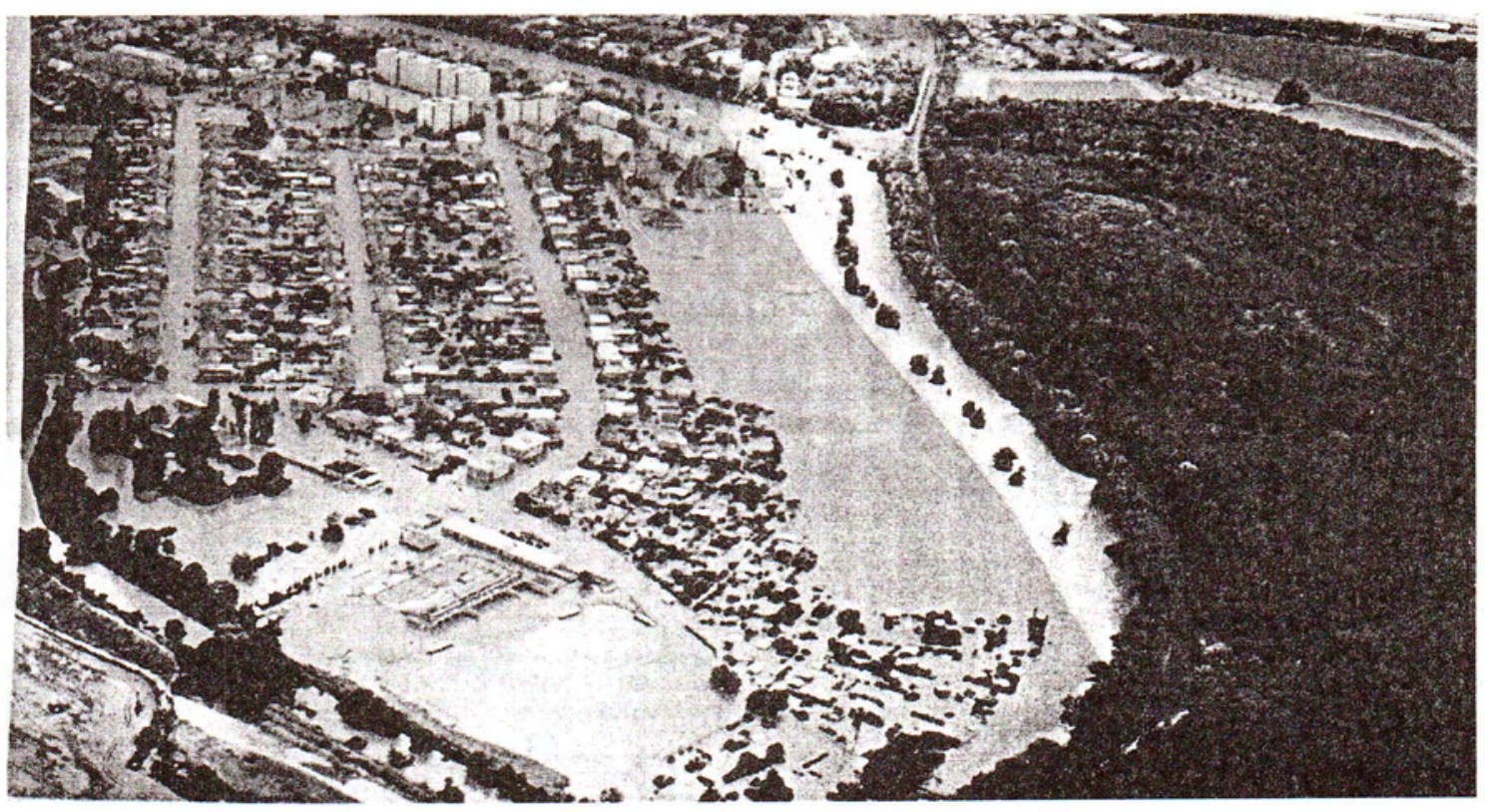

Fig. 1: Choceň flooded during the flood in 1997 (Elbe River Board, 1997)

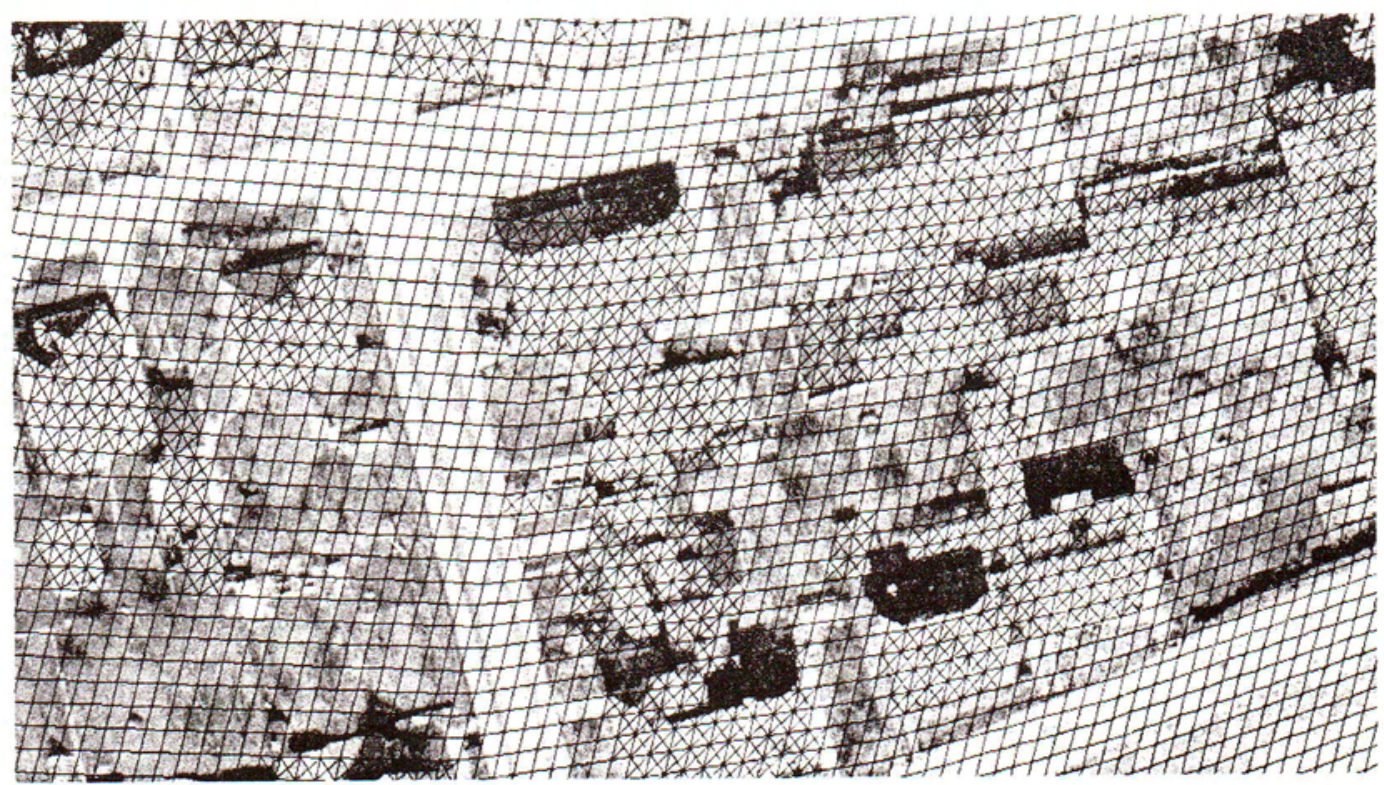

Fig. 2: Detail of the computational grid

and other obstacles were blocked out, and the boundaries of the blocked sub-domains were then treated as vertical walls during the simulations. Fig. 2 shows one detail of a small computational grid part of the Chocen 2D model. The crossed rectangles represent the blocked out computational cells.

The terrain approximation in the final numerical model was created with help of a digital terrain model created on the basis of an evaluation of the aerial snaps. The raw digital model data had to be complemented with the topography of the river channel and some other geometrical entities refining the terrain representation in the model. The aerial photos were taken in the summer of 1998 by Argus Geosystém Ltd. The evaluation of the photos was done by Topograf Ltd., Prague, in order to create a Digital Terrain Model (DTM). The raw data includes the elevations of all breaklines and also terrain elevations at a spacing of 10 metres. The declared data accuracy is $0.5 \mathrm{~m}$ in the horizontal direction and $0.25 \mathrm{~m}$ in the vertical direction

The aerial photo DTM data was complemented with survey information: eighty cross-sections at intervals of 50 to $100 \mathrm{~m}$. The cross-sections at hydraulic structures as well as the geometry of the structures themselves were specifically surveyed. Missing topological information in small parts of the terrain outside the evaluated aerial snaps also had to be added to the terrain data, using maps on a scale of 1:5000. All these changes and refinements were performed interactively, with the aid of the model preprocessor. Finally, the terrain data was interpolated to the nodes of the computational grid. The final assembled model is graphically documented in Fig. 3, which contains a 3D view of the model geometry (with the geometry of the buildings and roads symbolically depicted). 


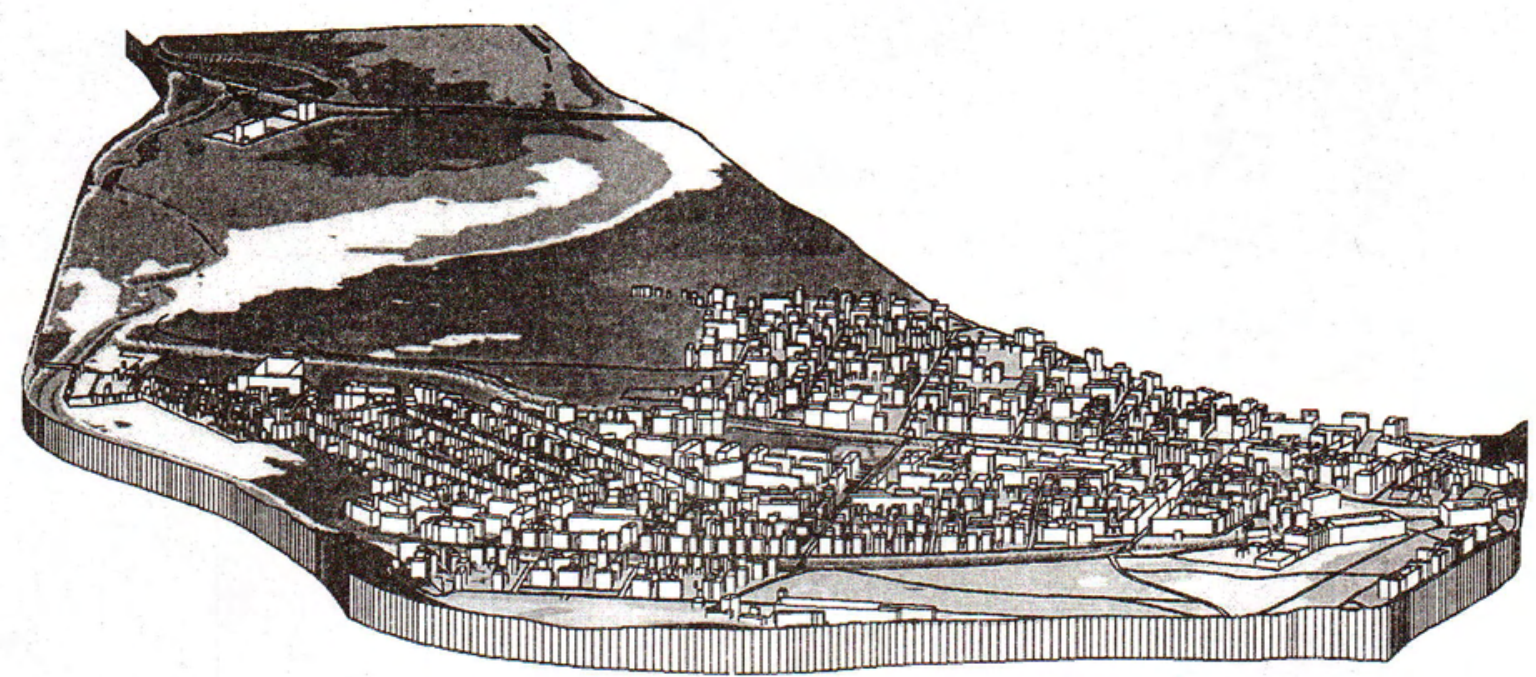

Fig. 3: A 3D view of the numerical model

\section{Boundary conditions}

The boundary condition prescribing the total inflow into the model was specified at the inlet boundaries along with the prescribed flow direction. Non-uniform distribution of the discharge along the inlet boundary was generated automatically inside the model algorithm according to the actual water depth at each boundary node. The fully developed turbulent flow with equilibrium between the production of turbulent kinetic energy and its dissipation was used as a boundary condition for the turbulence parameters. At the downstream boundary, the water elevation was prescribed as a boundary condition. For velocities and turbulent parameters a Neumann type boundary condition was used, assuming null derivatives of variables in the normal direction.

\section{Model calibration}

The model was calibrated using the available calibration data. During the calibration a discharge equal to the peak discharge of the 1997 flood was simulated, which is almost equal to the 100-year flood discharge. Sub-domains with different characteristics of hydraulic roughness were identified using aerial photographs and other available information. Fifteen different zone types were used. The corresponding computational cells for each zone were interactively identified in the computational grid and were given appropriate Manning coefficient values. The values of the roughness coefficients were adjusted by trial and error during the calibration simulation runs, with the aim of getting the best approximation of the observed water levels. The spatial distribution of

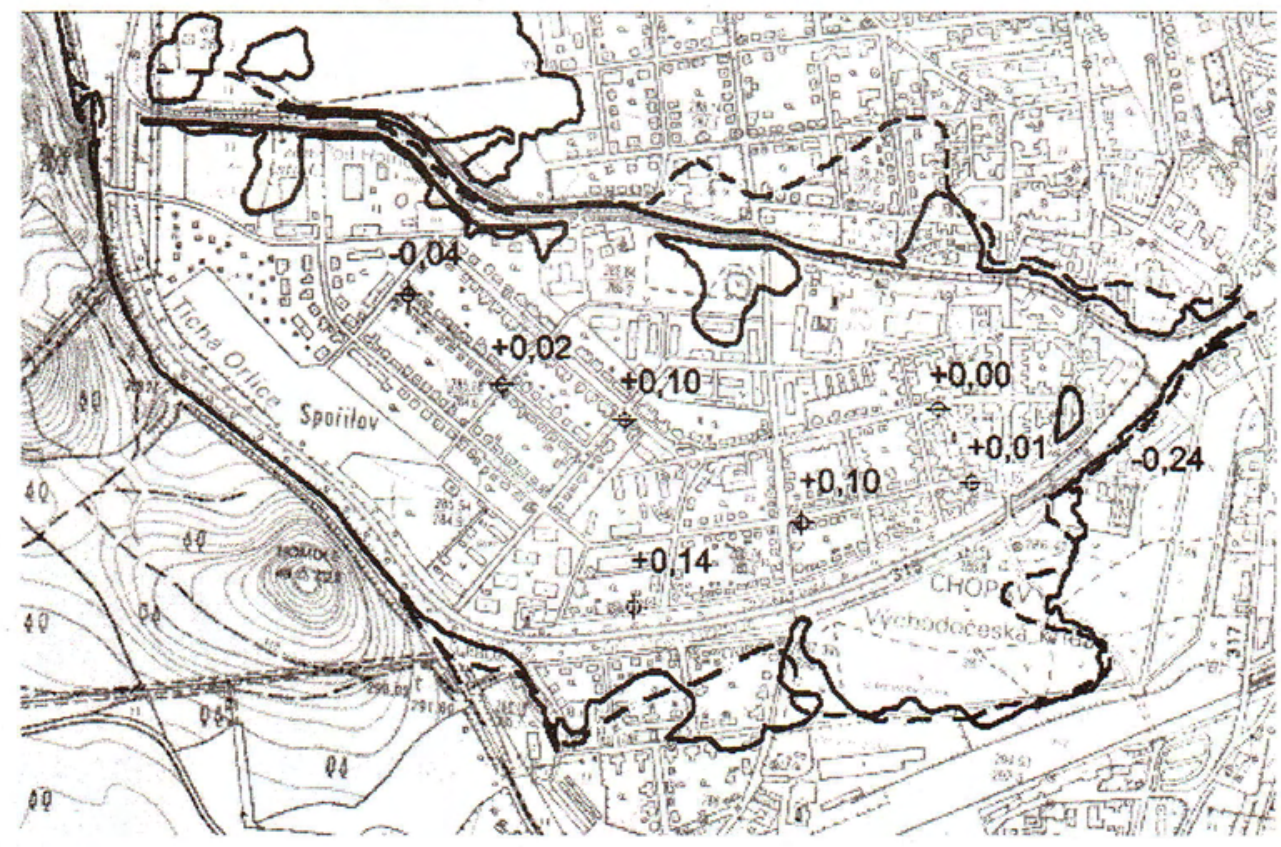

Fig. 4: Model calibration results 
the calibration points is shown in Fig. 4, together with a graphical evaluation of the final calibration results. The calibration results are expressed as the differences between the calculated and observed water levels. In the same figure, there is a comparison of the observed (dashed line) and computed (solid line) extent of the flood.

\section{Evaluation and utilization of results}

In order to make practical application of the numerical model easier and more efficient, a system of pre- and post-processing tools for the FAST 2D model has been developed. The system, called PREFAST [3], is oriented towards the use of personal computers, and was programmed as an application based on the $\mathrm{ADS}$ (AutoCAD development system) for AutoCAD graphical software. The system inherits interactive user-friendly tools with a graphical interface for all steps of the model design - grid generation and modification, creating, editing and exploiting the digital terrain model, specifying obstacles, specifying the distribution of bottom roughness coefficients - and for a graphical evaluation of the numerical simulation results.

The complete set of standard graphical interpretations of the simulation results includes:

- streamlines,
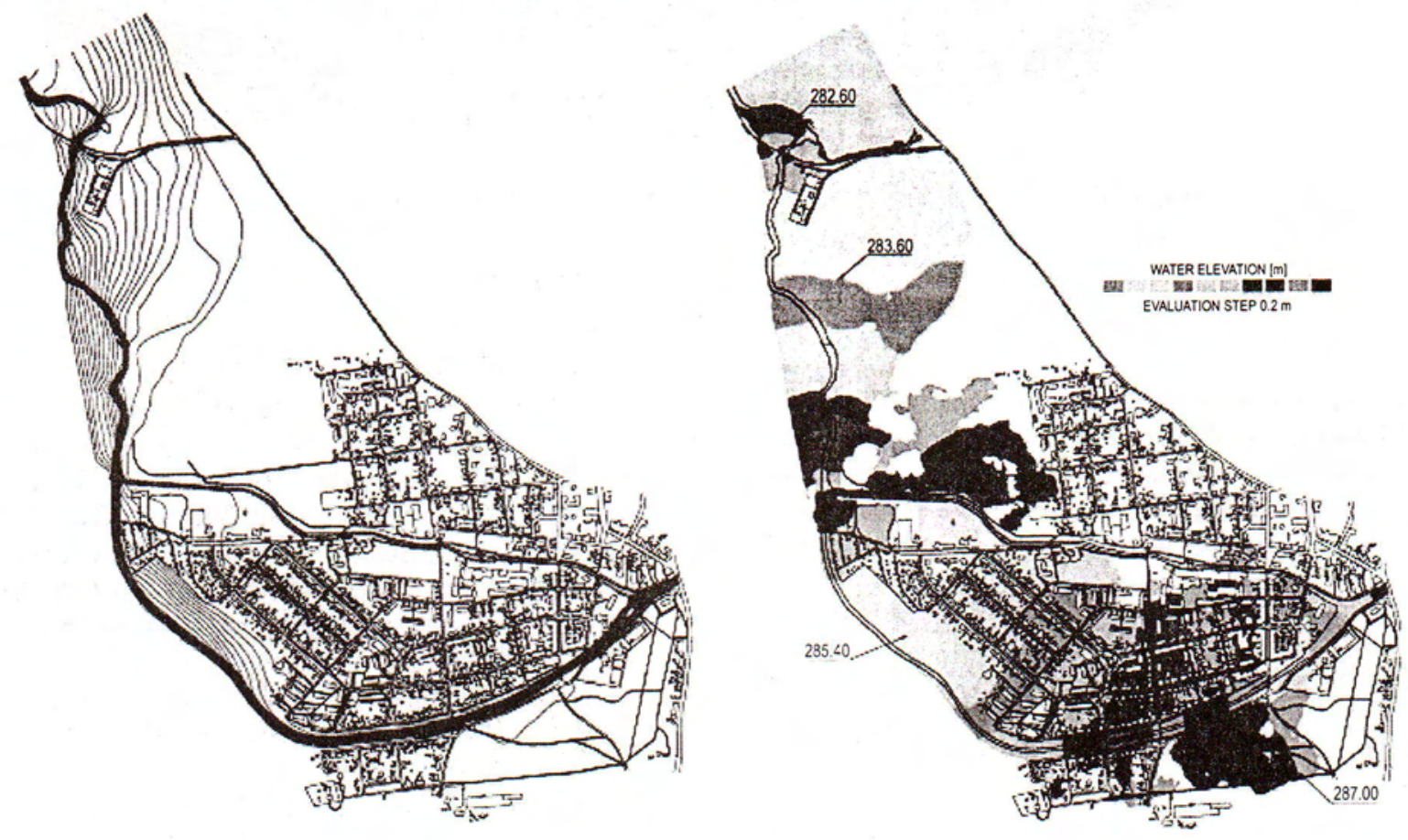

Fig. 5: Simulation results for the July 1997 flood event (streamlines and water elevations)

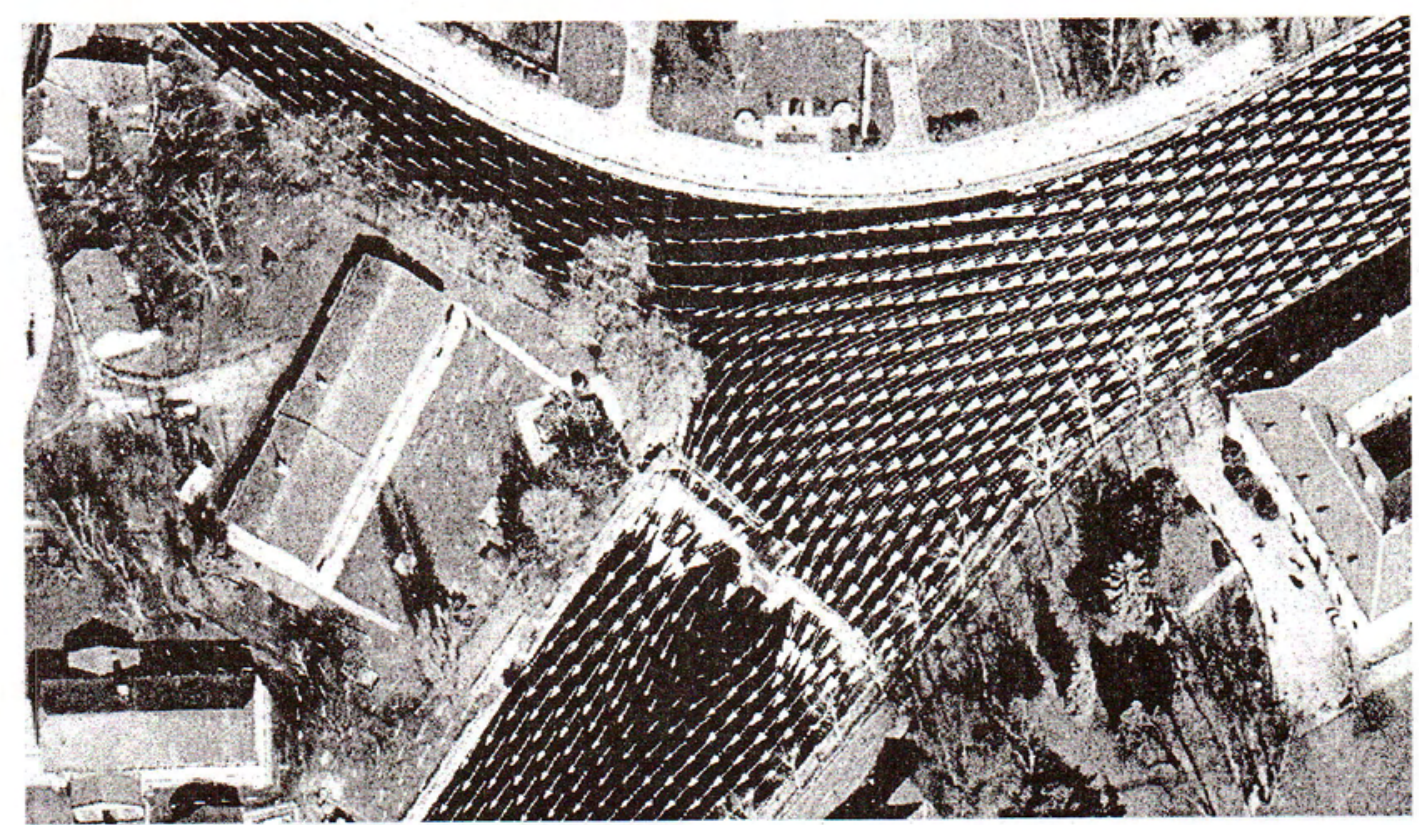

Fig. 6: Example of a detailed evaluation of results - the velocity field at the location of a flow split 


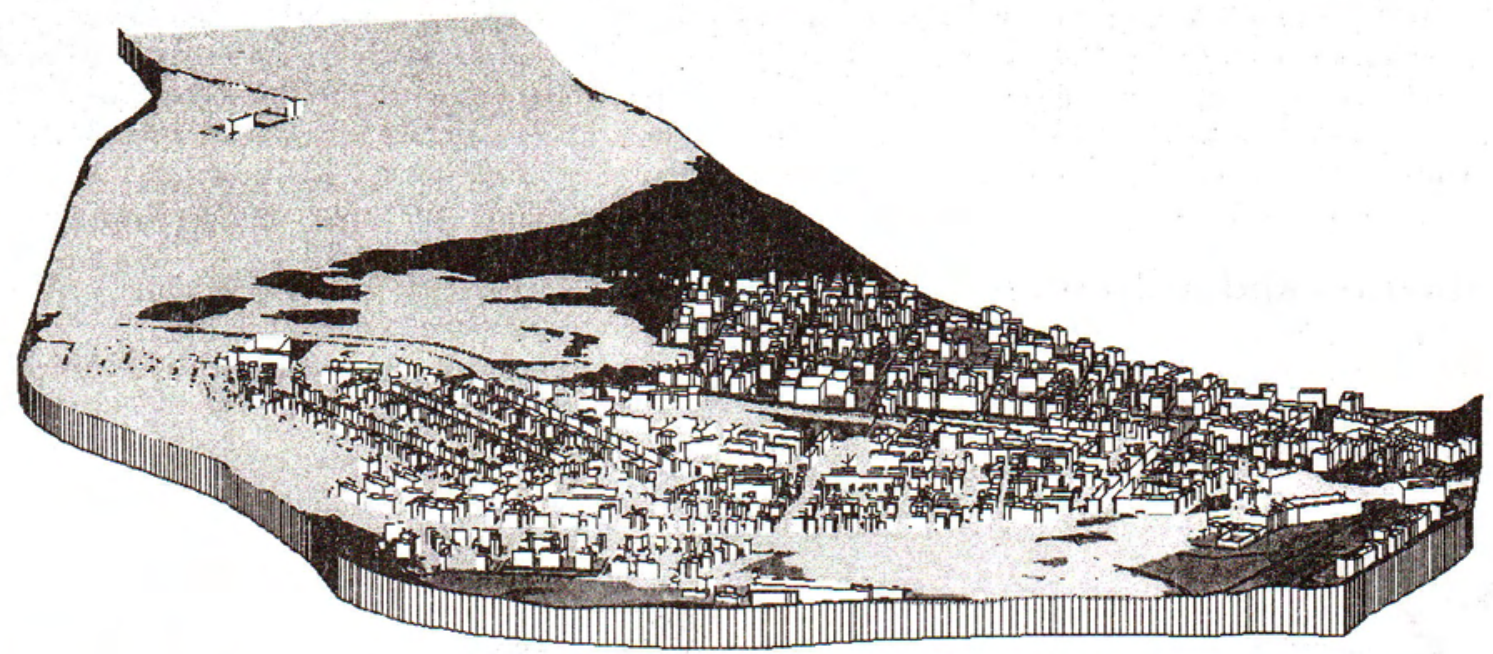

Fig. 7: Example of complementary presentation of results - a 3D view of the extent of the flood

- water elevations,

- water depth,

- flow velocities.

This standard evaluation set (flood hazard maps) provides detailed information about the spatial distribution of flood flow characteristics, and enables the analyses of flood flow conditions in the whole flooded area. The results enable complex flood evaluation, including for example the identification of main flow paths, specification of active and passive flood flow zones, evaluation of flood intensities, identification of weak points in the system, and recognition of main obstacles influencing the flood flow. Moreover, the primary results can be further used as input data for more complex flood analyzing methods, i.e., flood risk analyses and flood damage predictions.

Together with standard flood hazard mapping, some other special graphical representations of the results can also be applied. These evaluations provide a more detailed analysis of the results and include for example a local evaluation of the velocity fields (see example in Fig. 6), or they can be used for visual presentation to the public (see the 3D presentation of the extent of the flood in Choceň in Fig. 7, as an example).

The results presented in this study document the current potential of very detailed and non-simplified numerical models of flood flow in domains with very complex geometry and in urban areas. Analog studies can be directly applied to practical problems encountered in water management and land-use planning, e.g., in formulation of guidelines for land use in flooded areas, categorization of flood planes, preparation of municipal plans, evaluation of impacts of human activities in flood plains on flood flow conditions, elaboration and evaluation of flood control projects, etc.

\section{Acknowledgements}

The authors would like to thank the Swiss Agency for Development and Cooperation (SDC) - Swiss Humanitarian Aid (SHA) unit for funding the FLAMOR project, which made this study possible.

\section{References}

[1] Valenta, P.: Numerical modeling of free surface flow. Floods: Forecasts, Watercourses and Landscape. Prague: Czech Technical University in Prague, 2002 (in Czech).

[2] Wenka, T., Valenta P., Rodi W.: Depth Average Calculation of Flood Flows in a River with Complex Geometry. Proc. of the XXIV IAHR Congress. Madrid, 1991, p. A225-A232.

[3] Valenta, P., Wenka, T.: Handbuch zum Programm PREFAST Version 3.0. (Handbook for the PREFAST Version 3.0 Program). Praha: Hydro Expert Praha, Karlsruhe: BAW Karlsruhe, 1996.

[4] Kuipers, J., Vreugdenhil, C. B.: Calculations of Two-dimensional Horizontal Flow. Report S163. Delft: Delft Hydraulics Lab., 1973.

[5] Rastogi, A. K., Rodi, W.: Prediction of Heat and Mass Transfer in Open Channels. ASCE J. Hydraulic Division, Vol. 104, No. HY3, 1978, p. 357-420.

[6] Majumdar, S.: Development of a Finite - Volume Procedure for Prediction of Fluid Flow Problems with Complex Irregular Boundaries. Report SFB 210/T/29, Karlsruhe: University of Karlsruhe, 1986.

[7] Rodi, W., Majumdar, S., Schonung, B.: Finite - Volume Methods for Two-dimensional Incompressible Flows with Complex Boundaries. Comp. Methods in Applied Mech. and Eng., Vol. 75, 1989, p. 369-392.

Ing. Petr Valenta, CSc.

phone: +420224354675

e-mail:valenta@fsv.cvut.cz

Department of Hydrotechnics

Ing. Jana Valentová, CSc.

phone: +420224354778

e-mail: valentov@fsv.cvut.cz

Dept. of Irrigatipon, Drainage and Landscape Eng.

Czech Technical University in Prague

Faculty of Civil Engineering

Thákurova 7

16629 Prague 6, Czech Republic 